\title{
TO CREATE A BETTER AND MORE PEACEFUL WORLD: INFUSING HUMAN RIGHTS INSTRUCTION IN PK-12 CLASSROOMS
}

\author{
Kimberley Daly ${ }^{1}$ \\ George Mason University, USA
}

\begin{abstract}
This article discusses an online graduate education course at George Mason University in the United States. The course, part of a certificate program for International Baccalaureate (IB) educators, focuses on infusing human rights instruction in PK-12 classrooms and provides teachers with additional methods and strategies to teach various subjects, disciplines, student populations, and cultural contexts. Although the course text centers on the United Nations Convention of the Rights of the Child (UNCRC), additional readings require students to consider other human rights documents, academic research concerning peace and human rights education, and classroom strategies. The teachers who complete the course are more confident working with human rights topics and the course encourages educators to think critically and connect issues at their grade level and in their current contexts.
\end{abstract}

Keywords: teacher education, human rights, human rights education, International Baccalaureate, international education

\section{Introduction}

Although the concept of human rights may date back to the time of the Persian King Cyrus the Great, most associate the international recognition of human rights with the end of World War II and the adoption of Universal Declaration of Human Rights (UDHR). The atrocities witnessed in Europe and the Pacific moved many to put in place specific language to protect human rights. Despite this, in most Western countries, students receive little education about human rights and teachers receive almost no formal training in their education programs concerning exactly how to infuse human rights education into classroom instruction.

Also, in many countries, standards-based education supersedes any movement to integrate human rights into curricula and teachers are left to their own ideas to integrate human rights education (HRE). In curricula that have a social justice component, such as

\footnotetext{
${ }^{1}$ Correspondence: 4400 University Drive, MSN 1E8, Fairfax, VA 22030. Email: kdaly1@gmu.edu
} 
International Baccalaureate (IB) Programmes, this standards-based approach can be in conflict with ideals such as international mindedness and the Programme's Mission Statement which "aims to develop inquiring, knowledgeable and caring young people who help to create a better and more peaceful world through intercultural understanding and respect" (International Baccalaureate, 2019, para. 4). Without explicit instruction, teachers can struggle to connect social justice goals and HRE to IB curricula and make meaningful connections for students.

Towards that end, this article discusses an online graduate education course offered at George Mason University (Mason), in Fairfax, Virginia. The course, part of a certificate program for International Baccalaureate (IB) teachers, helps educators learn how to infuse human rights instruction into PK-12 settings all over the world and facilitates the development of lessons that they can use in their own personal contexts.

\section{Theoretical Framework}

Although the UDHR was adopted in 1948, there was no real movement in the field of HRE until the late 1970s when participants at the International Congress on the Teaching of Human Rights created a definition that began to establish it as a field (Suárez, 2007). In that definition, HRE was called to promote tolerance and respect, teach human rights, and raise awareness about how to secure human rights both nationally and internationally (Suárez, 2007). Since that time, the international human rights movement has greatly expanded with additional treaties and calls for HRE in schools (Suárez, 2006; Tibbitts, 2015). Governments, international organizations, and nonprofit organizations have had ongoing conversations concerning HRE and some organizations have been established solely for the purpose of promoting the implementation of HRE (Stone, 2002; Suárez, 2007).

In addition to being present in conversations among governments and organizations, HRE has also found its way into education. Unfortunately, HRE is often included in curricula without any explanation of why it should be taught (Meyer, Bromley \& Ramirez, 2010). Despite this, academic interest and research in the subject has grown and groups of educator networks have been created to promote and provide resources to those who work with HRE (Tibbitts, 2015; Suárez, 2007).

For those working in ministries of education and creating educational policy around the world, the topic of HRE is definitely more present since the UN Decade for Human Rights Education (1994 - 2005). References to HRE have been increasingly incorporated into curricular documents and educational policies and international bodies frequently reference HRE in global educational literature (Hantzopoulos, 2016). Although HRE is not always fully implemented, it is often defined as a means to promote human rights; ministries of education often approach the enactment of HRE through policies tailored to their specific contexts and cultures (Hantzopoulos, 2016).

The exception to this is the United States - despite being a signatory of the UDHR, on a national level, there is no mention of human rights or HRE in any official educational policy documentation (Hantzopoulos, 2016). States, and not the national government, determine curricula but must comply with national policies in order to receive federal funding. Additionally, states must set curriculum standards and report on progress to the national government. The U.S. government pulled out of the UN's Human Rights Council in 2018 and has not ratified seven treaties related to human rights (The Advocates for Human Rights, n.d.).

Because there is no directive for HRE from the U.S. government, many other factors have influenced school curricula. Parents and other groups can challenge schools to influence 
policy and others may also try to promote specific types of curriculum such as science, technology and mathematics, human rights, or focus on advanced coursework (Bajaj, 2012; Hantzopoulos, 2016); all have varying degrees of success in the United States depending on location and often, the political climate. When human rights is put into state curricula in the United States, it is often integrated in the content area of social studies and taught from a historical approach without a focus on skills, attitudes, advocacy, or application to current contexts (Hantzopoulos, 2016; Mayersen, 2018; Tibbitts, 2015).

Language and terminology also matter here. In the 42 American states that required or recommended that HRE be included in standards, just over 30 used the term human rights. Some states use the term civil rights and place their focus there rather than what is traditionally thought of as HRE. The majority of focus for most states is on human rights in an international context rather than within the United States (Sirota, 2017; The Advocates for Human Rights, 2016). Although HRE standards are not present in curricula, many other groups make materials available to teachers online and in print.

For teachers though, it is not only enough to be able to teach HRE. They also need to have training in HRE. Many beginning teachers do not receive any formal or informal instruction in HRE and experienced teachers who want to teach HRE often need to seek out professional learning. Some teachers starting out have fears of backlash from parents or administration in pursuing HRE and worry they will create student activists that will get them in trouble. Sometimes teachers fear that personal or local values may contradict the teaching of HRE. A values and awareness model of teaching HRE (Tibbitts, 2002) can sometimes mitigate these issues but does not always alleviate the concerns that teachers have. Even for teachers who are trained in social justice issues, teaching HRE, integrating it into lessons, and making it meaningful for students can seem like a daunting task. With these things in mind, the following sections examine the genesis and the current form of a graduate education course in HRE for International Baccalaureate teachers and outlines the outcomes and impact of such a course for teaching HRE.

\section{Creating a Human Rights Course}

On its face, Methods and Strategies for Teaching in IB Schools does not sound like human rights course. Originally, it wasn't. It began in 2008 as an educational methods course for teachers working in International Baccalaureate (IB) schools and is currently the third course in the Mason's Certificate in International Baccalaureate Teaching and Learning. The graduate education students taking the course are experienced teachers and can come from anywhere in the world; they may work in a national or international school, be teaching any grade or subject from pre-kindergarten to grade 12 and even be an administrator such as a head of school.

The students are all versed in the IB Programme, led by the IB Organization which maintains four separate curricular programs - the Diploma Programme (DP) established in the late 1960 s for students in the final two years of secondary school, a Middle Years Programme (MYP), established in 1994 for students 11 to 16 years old, a Primary Years Programme (PYP), started in 1997 for students three to 11 or 12 years of age and finally, the Career Programme (CP) offered for students in Diploma schools since 2012 and focused on vocational education. Common between all four programs is inquiry-based instruction, social justice, service learning, reflection, and international mindedness. There is also a set of common character traits called the Learner Profile that each program seeks to develop in students. HRE can be connected to the IB through the Mission Statement as well as through 
curricula and service learning requirements in each program (Hill, 2006; International Baccalaureate, 2019; Wilkinson \& Hayden 2010).

The program where the course is situated is fully online. As the course evolved over time, I wanted to transition the course from a straight methods and strategies course to one that integrated the human rights and social justice goals of the IB programme and as a result, reimagined the course from a basic educational methods course to one where HRE would be integrated with the teaching techniques that had been traditionally in the course. When I began thinking about this, I looked back at my own K-12 experiences; when I was asked to incorporate something new into my classroom teaching, it was always easier to do so within existing curricular activities. I also knew it was also easier to start small and then create more lessons and units as I gained confidence and familiarity with a topic. As a result, I built the class with time for my students to both explore HRE and also align their practice with the IB goals and standards they worked with daily. It gave the students dedicated time to consider how to integrate HRE into their individual contexts and classrooms. Finally, it provided these experienced teachers with a deeper way to integrate how they were learning different classroom practices. The forum of my course also created a safe space for them to test out ideas and develop lessons as well as ask questions about concerns. They had the space to think critically about human rights issues and float ideas without the fear of reprisals from parents or administrators while they tested out lessons, project ideas, and action plans.

\section{Researcher Perspective and History with the Course}

When the Methods and Strategies for Teaching in IB Schools course was first offered in 2008, I was part of the first cohort of students to take the course. I was also part of the first cohort of students in the Certificate in International Baccalaureate Teaching and Learning Program. I did not finish the program, and instead, chose to enroll in a doctoral program. I first taught the course in 2011 and have been teaching it consistently since that time.

The course is currently offered each spring at Mason. Spring 2019 was my $10^{\text {th }}$ time teaching the course and the sixth time since it has been taught through the human rights lens.

\section{The Core Text and Other Readings}

As our program draws teachers from all over the world who may work in any grade from pre-kindergarten through grade 12, it was important to ground the course with a text that spoke to multiple grade levels of students as well as focused on lessons and resources through a human rights lens. For this reason, the text, A Critical Inquiry Framework for K-12 Teachers: Lessons and Resources from the U.N. Rights of the Child(Allen \& Alexander, 2012) was chosen. The edited book presents several cases at various grade levels that ask the students to critically interact and reflect on the United Nations Convention of the Rights of the Child (CRC). Although the United States is only one of two countries not yet to ratify the CRC (South Sudan is the other), the treaty does address issues and ideas important to educators the commitment of teachers to honor students and their identities, and the importance of educators listening to student voices, hearing their concerns, and providing them with safe spaces that not only support their learning but support and enrich their development as individuals. The book also supports the teachers' own explorations and critical inquiry into social issues including discrimination, language, culture, and global citizenship. Many of these same topics also overlap with the IB curricula that the teachers in our program work with daily. 
In addition to the core text, I use supplemental readings and videos to highlight specific issues during certain weeks. Readings are drawn from human rights documents from various parts of the world, IB documents concerning student diversity and inclusion, human rights materials from nonprofit organizations around the world, and materials for teaching HRE. Students also read some scholarly literature concerning HRE to provide some initial background. Every semester the course is reviewed and the materials reassessed for inclusion in the next iteration. Students also have the opportunity to provide written (qualitative) feedback to me through a detailed post-assessment that is outside of the regular course evaluation system. The post-assessment allows me to ask questions regarding specific text choices and assignments as well as ask students to comment about individual modules while the Mason evaluation is less individualized to specific courses.

As a result of student feedback, I have added several videos to the course so that students can have models of others who exemplify positive approaches to human rights and social justice. Several of the videos in the course are also suitable for the teachers to use in their own classrooms; two of the favorites have been an extended interview Malala Yousafzai did with The Daily's Show's Jon Stewart in 2013 and the speech Severn Cullis-Suzuki gave at the Earth Summit in 1992. Last year, Greta Thunberg's TEDxStockholm talk was suggested and now has been added to the course. Students noted that it was important to be able to show their students models of adolescents advocating for human rights and change. By providing real-life examples that were the ages of their students, teachers thought it helped their own students see themselves as advocates and protectors of the world too.

\section{The Discussion Board}

As our program is fully online, probably the most important mode of engagement in the course is the Discussion Board. Mason uses Blackboard for its Learning Management System (LMS) and the Discussion Board is integral for not only organizing the course, but working with students in several different time zones. All of the courses in our program are asynchronous. This allows students who may be several hours ahead of the main campus in the United States to be able to work within the class alongside those who may be closer to campus. My goals for the Discussion Board are twofold; it should serve as a safe community for the students for the time of the course to explore the topics of HRE and it is a place for ongoing critical reflection of professional practice.

Currently, each week is called a module. For each module, students have required readings or videos, and may possibly have an assignment to do. To anchor that work, students are asked to respond to questions or complete tasks on the Discussion Board. During the week, I also interact with the students, ask questions, respond, and try to probe their thinking a little more, providing additional references as needed and posting links to media if current events become relevant to the discussion.

\section{Introducing Human Rights and HRE}

The first week, students are introduced to the topics of human rights and HRE through a variety of means. As I do not always know where my students are from or teaching prior to the first time they log into Blackboard, I also do not know what familiarity they have with the topic of HRE. Because of this, I ask students to watch a video concerning what human rights is; the video is short (under 10 minutes) and is something that they can possibly use in their classes. Following that, they are asked to peruse various human rights documents including the UDHR and charters and conventions on human rights from Africa, Middle East, the Americas, and Europe. Finally, they are introduced to the CRC through the first 
chapter of the Allen \& Alexander (2012) text which explains the structure of the book and issues the first reflective invitation. The concept of HRE is introduced to the class through a discussion of models of HRE (Hantzopoulos, 2016; Tibbitts, 2002). Students are introduced to the value and awareness model, the accountability model, and the transformational model and asked to consider how they might be able to incorporate them in their classrooms. Because of individual contexts and locations, some students cannot aspire to transformational HRE but can pursue HRE in a value and awareness model.

The value and awareness model serves to teach students general human rights theory, history, and content with some attention to promoting positive behavior. There may also be some attention to the learner's rights (Tibbitts, 2017). This approach is sometimes better for some of our students who teach in countries where HRE is not specifically defined or is quite narrowly defined. The transformational model of HRE teaches human rights with a strong focus on the learner, appeals to personal value systems, and aspires to create agents of change (Tibbitts, 2017) - students who will create a more peaceful world. This fits in with the IB Mission Statement and involves students taking a critical stance in light of the issues discussed.

Students' initial understandings of human rights and HRE often include connecting the ideas and documents to the IB programmes in which they teach and the overall philosophy. One middle school teacher said, "IB programs challenge students to think and human rights are an important part of expressing one's views - students should understand that they have the right to take a critical stance on important social issues affecting them."

\section{Getting into the Issues}

Once students understand the models of HRE, the course starts to build teachers' understanding of various issues that they might be able to discuss in their own classrooms. The first issues we tackle are poverty and power while also discussing action. As the students who take this course are often a mix of those who teach in the United States and those who teach in international schools abroad, there are often different perspectives concerning poverty and power as school contexts can be quite different. For instance, teachers who work in lower socio-economic or Title I schools in the United States can see extreme poverty but some teachers who work in the international school system may have students who do not experience poverty at all on a day to day basis. The question I ask in class is how can we get students to understand and reflect on issues of poverty and power, especially when they may not encounter these issues in their daily lives?

The Allen \& Alexander text (2012) invites teachers to approach the question of poverty through several articles of the CRC including Article 17 - Children have the right to information important to their well-being, Article 24-Children have the right to safe drinking water, nutritious food, a clean and safe environment, and Article 27 - Children have the right to a standard of living good enough to meet basic needs (Office of the High Commissioner for Human Rights, 2019). To make the topic relevant for students at younger ages, some of the students in my class have framed the topic in different ways, including discussing fairness and equity. One student said:

We can teach children to be aware of issues such as poverty, race, and power by using literature and videos that are written and created from different perspectives. At our school, most of the children come from affluent backgrounds and may not have first-hand knowledge about different social 
issues...Another powerful teaching method is to create simulations where students can experience sensitive issues.

One fifth grade class, for their exhibition (a component of the PYP), studied homelessness. The teacher set up a night where they slept in boxes overnight with having only basic supplies. She also had the local police come and act out how they deal with the issue. The children came away with a deeper understanding of how it felt to be homeless and took action to help raise awareness. Another student who worked with elementary children said:

One of the challenges of encouraging an awareness of poverty amongst students - like mine - who do not live with it or see the effects it has on others, is that the human element is detached from the concept. The word carries empty meaning. They may see photos of poor children in Red Crescent posters and understand what is happening, but the photos elicit no emotional response. Educators must humanize the concept of poverty.

The students in the class often create inquiries and opportunities for their own students to understand the various issues being tackled in the class. Other Discussion Board questions ask students to create lessons and find resources for tackling an issue. For some students, this is difficult because of their subject area but in the time I have been teaching this course I have found that most disciplines can be connected to HRE. It sometimes just takes a little searching to make the connection.

In addition to discussing poverty and power, one of the most successful modules each year revolves around the discussion of rights to culture, identity, and freedom of thought. It aligns with CRC Article 8 - preservation of identity, Article 12 - Respect for the view of the child, Article 13 - Freedom of expression, and Article 14-Freedom of thought and religion (Office of the High Commissioner for Human Rights, 2019). Using the ideas of Indian anthropologist M.N. Srinivas, the students explore how one becomes thrice-born (Cole, 2012). As many of my students work with international and mobile populations, the teachers were in a unique position to delve into the question of where home is for these students. Depending on level, students often approach this in different ways and also, explore their own culture in the process. One student said, “...the concept of first, second, and third birth has helped me frame how we can work with students as a whole class as well as individually to be more aware of their own place in the world." Additionally, another student said, "The most important things teachers can do to help students explore issues of culture and identity in classrooms is to begin the dialogue, create awareness, and model acceptance."

Although the topics of the course do fluctuate, the course has consistently had modules focusing on poverty and power, identity and culture, the right to an education, student diversity and the rights of minorities, and taking action. In an IB context, the action module fits in nicely with the service learning goals of Creativity, Activity, Service (more commonly known as CAS in the DP), the Personal Project in the MYP, and the Exhibition in the PYP. It also connects to the transformational model of HRE - creating agents of change (Tibbitts, 2017).

\section{HRE in Math?}

Over the years, I have had several math teachers in this class and they all start out the course wondering how they will apply any of the topics we are discussing in their own 
classroom contexts. At first, I admit, I was a bit worried but each year I am more and more surprised by the ingenuity of my math teachers to apply the topics to their classes. In order to get students to think critically about poverty, they designed activities relating to how to make a conjecture. They look at how poverty is defined statistically and how different measures of poverty are compiled and used. They also ask their students to consider the moral, ethical, and social implications of statistical measures of poverty and their use. One of the secondary math teachers considered her subject area in relation to student identity saying:

Identity regarding math stems from factors such as previous math experiences, their parents' attitudes towards math, and peers' view of math...Having students share their various views of math could be helpful in redefining how students think about their role and identity in a math classroom.

On a simpler level, those who work with elementary students have incorporated human rights topics into lessons concerning addition and subtraction by teaching students what it costs to feed a family of four or even one person. Food is often something students can connect to easily at any age.

\section{Assignments and Learner Engagement}

The main assignments for the course are consistent weekly participation on the Discussion Board, a critical reflection journal, and a multimedia inquiry project. Additionally, students need to complete an instructional activity analysis and paper and a strategy video but these two assignments may not specifically be connected to HRE and will depend on the student's individual context at the time of completion. Some students in our program may not be teaching at the time and need to be placed in classrooms to complete their final assignment. This may not provide them with the flexibility to design lessons and they may need to work with the sponsoring/cooperating teacher to teach a lesson that will fit into the grade level framework, standards, or fit some other additional requirements.

Critical Reflection Journal. This journal is a space for students to reflect on the readings and make connections to how they might incorporate the topics discussed in class into their own personal classroom contexts. The journals are not really a research paper as they are short (three pages maximum) but they ask students to connect a given week to what they are thinking and make sense of what they are reading. Students often use the journal to start to consider how they might start to introduce HRE in to the classrooms or improve their practice in terms of the topic. For instance, during one module concerning culture, a student discussed how she needed to consider the ways in which she was respecting and celebrating the cultures of all of her students and not just the majority.

The Multimedia Inquiry Project. This project has become my favorite assignment for the course. This assignment is designed to get students working with the topics contained in the Convention of the Rights of the Child (CRC). Students design a presentation concerning one of the broad topics of the CRC as if it can be presented to a class of students on their level. They can design the presentation with any subject in mind - history, literature, mathematics, etc. In an IB context, this also allows my students to tie in connections to international mindedness, the IB Learner Profile, interdisciplinary themes, service learning, and other broader issues. The project also requires students to prepare a separate list of resources for colleagues to use as a starting point should they want to develop further information about 
the topic chosen. Students generally like this project because of the interdisciplinary nature of it. The project allows students to be creative, tie multiple resources together, and connect subjects to overarching IB themes. About the project, one student said, "The Multimedia Project really helped me to consolidate my learning. The feedback I received helped me to see better how I could link the UDHR and CRC to my subject area."

\section{Reactions to a Human Rights Course}

When I started teaching this course from a human rights lens I knew the topic fit in with IB goals and the Mission Statement, but I wasn't quite sure how the students would react. The reaction is generally very positive once students wrap their minds around how HRE can be done with their individual students in their own contexts. As one student stated:

I found studying the course in the context of the CRC very useful and I thought it was valuable as an IB teacher because it made me think about the rights of children regardless of which background they came from. I learned new strategies during this course and began to view education more as a human right because of the projects and modules we completed.

Another student who also had children of her own noted:

While I was aware of the IB's emphasis on international mindedness and global citizenship I noticed the impact on my two children's learning. It did not come to mind that the UN Declaration of Human Rights and CRC could be used as tools to deliver the message in the classroom. It was very enriching to explore the various invitations for inquiry in the textbook.

Even for students who noted that human rights was not currently part of their curriculum, the course provided them with ways to think about other issues such as diversity, environmental issues, waste, and fairness. Toward that end, one student said, "I think that this course gave me a lot of valuable ideas on how to discuss multiculturalism and international-mindedness in the classroom, and I am looking forward to try some ideas we discussed with my young students.”

\section{Positive Outcomes}

I suspect there are more than three positive outcomes of the course but I also think some outcomes come later, when students return to their own classrooms. The ones I see while the students are with me include: (1) collaboration, (2) real-world issues, and (3) interdisciplinary thinking.

Collaboration. First, the online environment that the course lives in is quite collaborative and safe and provides students with a forum to not only test out ideas for lessons but to discuss thoughts concerning HRE and the issues in the modules. A community is created among the students. As our program is small and this topic is quite focused (also, as a reminder, this is the third course the students have been in together), the students in the class create a community of practice concerning HRE as it can be applied to teaching in IB programs. Although each student teaches in a different subject and different classroom context (and in various countries) they are very willing to help each other out as a sounding board to collaborate concerning ideas for HRE, resources, materials, and questions. Over the 
time of the course, it is not uncommon for students to share materials on both the Discussion Board and through email and I maintain a Miscellaneous Items of Interest folder in the course for items students share as well as for things I find during the course that pertain to either the weekly discussion or current events that hit upon course activities. This has also led to the course becoming an evolving experience for the students, with me changing it a bit each time it has been taught, and no cohort experiencing the course the same way as I build upon the previous year. I, too, learn more about HRE with each iteration of the course.

Real-World Issues. As the students in the course are teaching in real classrooms in real schools, world events can be helpful in our weekly discussion. Examples of this would include incorporating discussion of Bring Back Our Girls (the Chibok schoolgirls kidnapping in Nigeria in 2014) into the module concerning the right to an education and tying Cape Town's water shortage issues in 2018 to a discussion about how children have a right to safe drinking water, nutritious food, and a clean environment. It is not unusual for either me or my students to find something in the news that they can connect to the topic we are studying. For instance, this past year an article from the Washington Post concerning how culture may impact a child's personality sparked much discussion among my elementary and ESL teachers (Putnam \& Gartstein, 2019). This helps students as they develop materials and lessons, as connecting the topics to real world events will help students see the connections between the abstract and the concrete.

Interdisciplinary Thinking. Another positive outcome is increased interdisciplinary thinking. Too often, with the exception of the elementary teachers, many students stay largely within their own disciplines and rarely move outside to work in others. In the course however, I see the students think in terms of multiple subject areas - working to integrate human rights topics into their disciplines smoothly. Often, it involves interdisciplinary or even transdisciplinary work and the teachers become more fluent in working across subject lines and boundaries. As one student wrote in her post-assessment:

[The course] showed me how to truly connect different subjects and merge them together by thinking outside the box and being creative. By focusing units on human rights, we could integrate various subject areas, focus on a topic, and address standards of learning.

Teaching HRE gets them out of comfort zones and enhances their classroom practice. This is extremely important for students too as they often have to combine disciplines to solve problems and accomplish tasks.

\section{Limitations}

Any course has its limitations. The three identified limitations include: (1) issues with activities due to the online environment, (2) issues with approaches to HRE due to school or national context and, (3) limited audience.

Issues with Activities Due to Online Environment. As the course is fully online, there are limitations to assignments/items that can be completed in an online environment. Also, as students are located in various time zones across the globe, it is not always possible to have a synchronous meeting at any point during the course. This limits the types of activities that can be completed and makes the Discussion Board a crucial tool for both communication and organization. As some students can be nearly a full workday ahead of the Fairfax campus, this limits options for real-time collaboration especially with working adults. Additionally, sometimes group projects are difficult as students need to plan for delays in exchanging 
information, documents, and shared work due to distance and individual professional obligations. Often, school schedules and varied teaching contexts impact students' contributions in real-time. When one student may be working on a project during a planning period in their school, another may be asleep and it is not possible to Skype to collaborate or bounce off ideas. As a result, I constantly explore options each year for new activities that can be done in the asynchronous environment, such as wikis, blogs, and other group presentation formats.

Issues with Approaches to HRE Due to School or National Context. Some students who take the class may be working in countries that do not have human rights as a defined part of the curriculum or what may be taught is defined very specifically. Therefore, a transformational approach to HRE may not be best in their contexts and a values and awareness approach (Tibbitts, 2017) would be much better. They complete the assignments and design lessons in a safer fashion than they would often like because of school or national contexts but are still benefiting from the materials provided in the course. For some students, the course provides a means to think about and teach HRE when they previously did not think they were able to do so. For example, they might develop lessons concerning the importance of clean water rather than exploring gender issues if it is not permitted in a specific school or country context.

Limited Audience. This limitation relates to the course in general as it is only offered through the Certificate in International Baccalaureate Teaching and Learning. Although the course ties in well with IB goals and aims, there is currently no way for additional students to take the course. Also, there is no other single course focused solely on HRE although some other courses in both the College of Education and Human Development and at Mason do focus on social justice and human rights in whole or part.

\section{Tips for Infusing Human Rights into a Course}

For those wanting to infuse human rights into a course, I offer four suggestions: (1) start small (2) be mindful of your students (3) seek meaningful and engaging materials; and (4) keep learning. These were really part of my guiding process in developing the course.

Start Small. This is not so much a suggestion for you but please keep it in mind for your students. Sometimes, teachers (especially beginning teachers) feel as if they have to do everything. But, everything they learn is something for their toolbox and they don't have to use it every day, every week. Your students need to learn that human rights topics can fit in naturally with their curriculum and yes, they can start small. One really good lesson or unit is often memorable, makes a difference for students, and can be built upon next year.

Be Mindful of Tour Students. It is important to be mindful of your audience. If some of your students are not practicing teachers yet, do they need more scaffolding? Do they need to see how HRE can connect to standards? Think about the students struggling with subject connections. Where can you help? Where might you fill the gaps? Also, please keep in mind that this may change from year to year.

Seek Meaningful Materials. This is really important. You do need to give students the foundations of human rights but you may need to be careful not to be too scholarly. This is a mistake I made at first as I included a little too much scholarly work in the course as not all of my students were used to reading it and it was overwhelming. Teachers need examples of materials that can be used in the classrooms they are in.

Keep Learning. Finally, teaching HRE is a journey and even after teaching the course six times, I find I can always learn more about HRE and human rights. I attend conferences, read papers, and actively look for things that my teachers can use in the classroom. I 
especially look for connections to human rights in math, arts, and elementary education as teachers of those subjects often find it harder to make initial connections. I am not sure my own professional learning will come to an end any time soon.

\section{Conclusions}

For IB teachers, infusing human rights instruction into classes complements the IB curriculum as it is already designed with HRE in mind. The IB Mission Statement, Learner Profile, and specific subject curricular documents already lend themselves to creating socially-conscious individuals who will advocate for peace and the human rights of others. Unfortunately, many teachers, IB or not, do not receive training on how to create specific lessons infusing human rights topics.

Although it is not always easy to grasp the content of human rights documents and these take time to digest, teachers are often willing to discuss and share experiences working with HRE in the classroom. When asked to connect to standards and curriculum, many connect to social studies and civics. Teachers can connect human rights ideas to knowledge and skills, values, attitudes, and action. They hope by teaching HRE that they can effect change in their students and eventually - create a better and more peaceful world.

\section{References}

Allen, J., \& Alexander, L. (Eds.). (2012). A critical inquiry framework for K-12 teachers: Lessons and resources from the UN Rights of the Child. New York: Teachers College Press.

Bajaj, M. (2012). From 'time pass' to transformative force: School-based human rights education in Tamil Nadu, India. International Journal of Educational Development, $32(1), 72-80$.

Cole, P. (2012). Becoming thrice-born: $10^{\text {th }}$-grade history students inquire into the rights to culture, identity, and freedom of thought. In Allen, J., \& Alexander, L. (Eds.). $A$ critical inquiry framework for K-12 teachers: Lessons and resources from the UN Rights of the Child. (pp. 109 - 126) New York: Teachers College Press.

Hantzopoulos, M. (2016). Restoring dignity in public schools: Human rights education in action. New York: Teachers College Press.

Hill, I. (2006). Do International Baccalaureate programs internationalise or globalise. International Education Journal, 7(1), 98-108.

International Baccalaureate Organization. (2019) Mission. Retrieved from https://www.ibo.org/about-the-ib/mission/

Mayersen, D. (2018). Teaching human rights online: An open access approach. International Journal of Human Rights Education, 2(1), 16.

Meyer, J. W., Bromley, P., \& Ramirez, F. O. (2010). Human rights in social science textbooks cross-national analyses, 1970-2008. Sociology of Education, 83(2), $111-$ 134.

Office of the High Commissioner for Human Rights. (2019). Convention on the Rights of the Child. Retrieved from https://www.ohchr.org/en/professionalinterest/pages/crc.aspx

Putnam, S. \& Bartstein, M. A. (2019, January 12). How different cultures shape children's personalities in different ways. The Washington Post. Retrieved from https://www.washingtonpost.com

Sirota, S. (2017). The inconsistent past and uncertain future of human rights education in the United States. Prospects, 47(1-2), 101-117. 
Stone, A. (2002). Human rights education and public policy in the United States: Mapping the road ahead. Human Rights Quarterly, 24(2), 537-557.

Suárez, D. (2006). The institutionalization of human rights education. In D. Baker \& A. Wiseman (Eds.), The impact of comparative education research on institutional theory (pp. 95-120). Oxford: Elsevier.

Suárez, D. (2007). Education professionals and the construction of human rights education. Comparative Education Review, 51(1), 48-70.

The Advocates for Human Rights. (n.d.). Human rights and the U.S.. Retrieved from http://www.theadvocatesforhumanrights.org/human_rights_and_the_united_sta tes

Tibbitts, F. (2002). Understanding what we do: Emerging models for human rights education. International Review of Education, 48(3-4), 159-171.

Tibbitts, F. (2015). Human rights education here and now: United States practices and international processes. Journal of International Social Studies, 4(2), 129-134.

Tibbitts, F. (2017). Evolution of human rights education models. In M. Bajaj (Ed.), Human rights education: Theory, research, praxis (pp. 69-95). Philadelphia: University of Pennsylvania Press.

Wilkinson, V., \& Hayden, M. (2010). The International Baccalaureate Diploma and student attitudes: An exploratory study. Journal of Research in International Education, 9(1), $85-96$.

\begin{abstract}
About the Author
Kimberley Daly, PhD, is an adjunct professor in the Teaching Culturally, Linguistically Diverse \& Exceptional Learners Program in the College of Education and Human Development at George Mason University. Since 2009, she has been affiliated with the Advanced International Baccalaureate (IB) Studies program, the first American IB educator certificate program authorized by the International Baccalaureate. She received her Ph.D. in Education from George Mason University in 2012. Daly has taught in various PK-20 settings in New Jersey, Virginia, and Ukraine. Her research areas include International Baccalaureate programs, human rights education, teacher education, international mindedness, and problem-based learning.
\end{abstract}

